\title{
EL DEBIDO PROCESO EN EL RÉGIMEN DISCIPLINARIO DE LOS INTERNOS EN COLOMBIA, ECUADOR Y ESPAÑA
}

Ángela Sofía Riaño Santacruz*, Jhon Freddy Páez Carballo**, Astrid Milena Calderón Cárdenas***

\section{Resumen}

En el presente artículo basado en el derecho comparado, señala el debido proceso en el régimen disciplinario de los internos en Colombia, Ecuador y España según su normatividad, jurisprudencia y doctrina, la situación actual que presentan los sistemas carcelarios de estos países. Se determinó que cuentan con unos derechos y garantías constitucionales según sus regímenes, que incluyen una protección y respeto al debido proceso para las personas privadas de la libertad; teniendo como conclusión que estos países cuentan con normas que protegen, regulan y preservan los derechos de las personas de los establecimientos carcelarios, el cual podría deducirse su calidad de garantistas. En el transcurso de la investigación realizada, se da a conocer las posibles soluciones de las diferentes leyes u ordenamientos, para mejorar la aplicación del debido proceso en Colombia por medio de los países de Ecuador y España.

* Estudiante de VII semestre del Programa de Derecho de la Fundación Universitaria del Área Andina, seccional Pereira. Integrante del Semillero de Derecho Penitenciario y Carcelario, adscrito al Grupo de Investigación GEIS. Correo institucional: ariano14@ estudiantes.areandina.edu.co

* Estudiante de VII semestre del Programa de Derecho de la Fundación Universitaria del Área Andina, seccional Pereira. Integrante del Semillero de Derecho Penitenciario y Carcelario, adscrito al Grupo de Investigación GEIS. Correo institucional: Jpaez31@ estudiantes.areandina.edu.co

*** Coautora: Docente - Abogada Especialista en Derecho Administrativo. Magíster en Historia y Doctoranda en Educación. Directora del Semillero de Derecho Penitenciario y Carcelario, adscrito al Grupo de Investigación GEIS de la Facultad de Derecho de la Fundación Universitaria del Área Andina, seccional Pereira. Correo: amcalderon@ areandina.edu.co 


\section{Introducción}

Esta investigación se basa en el derecho comparado y su normatividad en el régimen disciplinario del sistema carcelario de Colombia, Ecuador y España, teniendo en cuenta el debido proceso en estos países. El derecho comparado cruza diferentes ideas y prácticas jurídicas que sirven para utilizarlas como referencia para la doctrina, la jurisprudencia y el legislador. Permite obtener un mayor conocimiento, comprensión de la materia objeto de estudio y contribución al derecho al observar cómo debería ser aplicado el debido proceso a las personas privadas de la libertad, recibiendo los resultados de los ordenamientos de otros sistemas jurídicos diferentes al colombiano.

\section{Planteamiento de problema}

El régimen disciplinario y el desarrollo del debido proceso en los centros penitenciarios, es un área a reforzar dentro del Estado colombiano, puesto que las personas privadas de la libertad pertenecen al sector más desfavorecido de la sociedad, cuyas vidas se encuentran atadas a unas rejas que los limita de una serie de derechos. Colombia tiene un sistema de Estado Social de Derecho, el cual propone garantizar los derechos esenciales de la sociedad, corrigiendo las desigualdades, promoviendo la inclusión y la participación, garantizando a las personas, individualmente consideradas o en grupos, que se hallen en situación de desventaja. Por tanto, no es justo que las personas privadas de la libertad se les vulnere uno de los pocos derechos y beneficios ofrecidos dentro de los cen- tros penitenciarios, como es el debido proceso. De acuerdo con lo anterior, se plantea según la metodología del derecho comparado, la siguiente pregunta: ¿cuáles son las diferencias y semejanzas del régimen disciplinario de los internos en Colombia, Ecuador y España desde la perspectiva jurisprudencial, normativa y doctrinal según el debido proceso?

\section{Justificación}

Es de gran importancia llevar a cabo este proyecto de investigación, ya que el derecho comparado es un método que permite observar las diferentes soluciones de los ordenamientos jurídicos, en este caso del debido proceso en el régimen disciplinario, en países diferentes a Colombia. Por tanto, es pertinente realizar este tipo de investigaciones, pues se ha ido indagando cómo rige este derecho en países diferentes a Colombia, tratando de llegar a una conclusión de porqué este derecho se ve afectado en ciertas situaciones $y$ cómo ha sido el proceso para que se vea reducido; puesto que en la actualidad, este es uno de los derechos más vulnerados por parte de los administrativos de los centros carcelarios en la aplicación de los mecanismos sancionatorios o disciplinarios y regímenes penitenciarios y carcelarios. Sin dejar atrás los conceptos determinados por los doctrinantes, la jurisprudencia obtenida sirve para ver la resolución de casos concretos.

\section{Objetivos}

Objetivo general: determinar las diferencias y semejanzas del régimen disciplinario de los internos, en cuanto al debido proceso en Colombia, Ecuador 
y España desde la perspectiva jurisprudencial, normativa y doctrinal.

\section{Objetivos específicos:}

- Identificar la normatividad del debido proceso del régimen disciplinario de los internos en Colombia, Ecuador y España.

- Analizar en la jurisprudencia las decisiones que involucran el debido proceso del régimen disciplinario de los internos en Colombia, Ecuador y España.

- Comparar la doctrina de Colombia, Ecuador y España, según el desarrollo del debido proceso del régimen disciplinario de los internos.

\section{El debido proceso en el régimen disciplinario de los internos}

En el presente trabajo se analizará el desarrollo del debido proceso en el sistema penitenciario y carcelario de países como Colombia, Ecuador y España, enfocado en examinar individualmente su normatividad vigente y fundamental, como su doctrina y jurisprudencia.

\section{Colombia}

Haciendo una retroalimentación con respecto a las políticas públicas expedidas en Colombia, a través del tiempo, acerca del debido proceso en el régimen disciplinario de los internos, nos demuestra la gran ayuda del Estado para mejorar las condiciones de vida y la no violación de derechos fundamentales de los reclusos en los centros penitenciarios. De acuerdo con lo anterior, es la población a la cual más se le vulneran los derechos fundamentales importantes para poder llevar una vida digna dentro de los establecimientos penitenciarios, como lo es el debido proceso, según lo afirma Rivera Agudelo (2009):

[...] los procesos disciplinarios que en forma administrativa adelanta la Dirección del Instituto Penitenciario y Carcelario (INPEC) o los consejos de disciplina, se debe decir que los mismos son violatorios del debido proceso y del derecho a la defensa, dado que en última instancia ello depende hasta del mismo capricho de los funcionarios encargados de la vigilancia de las personas privadas de la libertad. (p. 23)

El debido proceso está consagrado en la Constitución Política de Colombia, el cual se aplicará a todas actuaciones judiciales y administrativas.

El régimen disciplinario de los internos se encuentra regulado en el Código Penitenciario Carcelario, Resolución 6349 de 2016 y la Ley 1709 de 2014. Este código establece que el INPEC expedirá el reglamento disciplinario de las personas privadas de la libertad con previo concepto favorable del Ministerio de Justicia y del Derecho, respetando el debido proceso y todas sus garantías.

Las sanciones disciplinarias que se aplicarán a las faltas graves y leves están estipuladas en el artículo 78 de la Ley 1709 que modificó la Ley 65 de 1993. Las faltas graves se impondrán realizando o atendiendo los requisitos de proporcionalidad, necesidad y daños causados, al contrario de la sanción de las faltas leves. Todo lo anterior parte de que ninguna persona privada de la libertad podrá ser 
sancionada por alguna conducta que la ley no menciona dentro de las estipuladas en el artículo 78 de la Ley 1709 de 2014, ni muchos menos dos veces por el mismo hecho. También, que estas faltas serán calificadas teniendo en cuenta las circunstancias que lo agraven o atenúen. Estas sanciones serán impuestas garantizando el debido proceso, ya sea por el Consejo de Disciplina o el director del INPEC y contra estas decisiones proferidas por ellos procederá el recurso de reposición, en subsidio el de apelación ante el Consejo de Disciplina correspondiente, presentándose así la garantía del derecho en cuestión. En pocas palabras, el director conocerá de las faltas leves y el Consejo de Disciplina de las graves y todas estas sanciones serán registradas en la Sistematización Integral del Sistema Penitenciario y Carcelario (Sisipec). También, se tiene en cuenta que el aislamiento no es permitido para el caso de sanciones disciplinarias, sino para ciertas causales establecidas en el artículo 80 de la Ley 1709 de 2014.

Debido a este tema, la Corte Constitucional ha emitido sentencias argumentando la protección del debido proceso, como la sentencia T-720/17, magistrada ponente: Diana Fajardo Rivera. Aquí, el accionante estipula que se vulneró el debido proceso en el centro carcelario Las Heliconias, ya que al momento de realizar una requisa grado tres, un grupo LGTBI propuso que les realizaran dicho procedimiento sin quitarse la ropa, a lo cual accedió el inspector jefe y se les permitió utilizar toallas, después, un dragoneante le dio un informe al director exponiendo que ellas cometieron una falta grave disciplinaria por faltarles el respeto a los dragonean- tes al momento de realizar la requisa y que en realidad no fue así y ellas fueron sancionadas. La Corte falló a favor de los derechos fundamentales de José David Benítez a la identidad de género, la dignidad y el debido proceso.

\section{Ecuador}

El debido proceso está plasmado en los convenios y tratados internacionales, normas constitucionales y en la Constitución de la República que lo promulga como un Estado garantista.

La Constitución Nacional de 2008, fundamenta el debido proceso como un derecho fundamental en su artículo 76: "En todo proceso en el que se determinen derechos y obligaciones de cualquier orden, se asegurará el derecho al debido proceso que incluirá unas garantías básicas". (Constitución Nacional [CN], 2008, art. 76). La cual busca dar eficacia a la ciudadanía y que los organismos estatales los cumplan.

El Código Orgánico Integral Penal tiene como finalidad establecer el procedimiento disciplinario de las personas privadas de la libertad con observancia del debido proceso y promover la rehabilitación social de las personas sentenciadas, que tiene como fin el garantizar el respeto a los derechos de los internos privados de libertad, que debe tener una convivencia armónica, seguridad de los centros y el cumplimiento eficaz de las penas. Las sanciones disciplinarias previstas en estos centros carcelarios le corresponden a la autoridad competente del centro, dependientes a la Constitución y la ley. 
El director es el encargado de los centros penitenciarios, donde podrá tomar medidas urgentes encaminadas a evitar o prevenir faltas disciplinarias, que deberán ser inmediatamente comunicadas a la autoridad competente del centro según corresponda. Estas faltas disciplinarias se clasifican en leves, graves y gravísimas, consagradas en el capítulo IV del Régimen disciplinario para las personas privadas de libertad. Las sanciones se impondrán dependiendo de la gravedad y reincidencia, las que deben justificarse en virtud de la proporcionalidad y características de las faltas cometidas que son: 1) Restricción del tiempo de la visita familiar. 2) Restricción de las comunicaciones externas. 3) Restricción de llamadas telefónicas. 4) Sometimiento al régimen de máxima seguridad. En los casos en los que estas faltas disciplinarias puedan considerarse como delitos, la autoridad competente del centro pondrá en conocimiento de la Fiscalía y se procederá conforme lo señala el citado Código. Este procedimiento para sancionar será breve, sencillo, oral, y se respetará el debido proceso y el derecho a ser escuchado por sí mismo o por medio de una defensora o defensor público o privado, de conformidad con las reglas pertinentes.

Una de las principales causas es la desigualdad, la falta de garantías laborales educativas, apoyo por los organismos del Estado y de esta manera influye en cierta forma en un aspecto ético moral y de marginalidad. Genera reacciones múltiples por parte de la sociedad, que se ven reflejadas en temas como la violencia, por lo cual fue necesario crear mecanismos de control como el sistema judicial y penitenciario.
El tratadista Ramiro Ávila Santamaría (2008) enfoca el problema de la rehabilitación social en las cárceles ecuatorianas, aduciendo que en los procesos privativos de la libertad se deben considerar tres principios básicos $\mathrm{y}$ fundamentales, $\mathrm{y}$ que su omisión necesariamente significa una vulneración a los principios constitucionales del derecho a la defensa, seguridad jurídica, debido proceso, tutela judicial efectiva y a la libertad. Estos tres principios son: ser oído y ser defendido; ser oído y ser presentado y ser oído en un plazo razonable. Al final, presenta algunas reflexiones a manera de conclusiones, en las que después de haber analizado la situación de los presos de Machala $y$ Cuenca, colige que en ninguna parte se respetan las directrices enfatizadas como parámetros de respeto o vulneración de los derechos de los reos; lo cual se empeora con la deplorable situación en que se encuentran las cárceles en cuanto a infraestructura y organización logística. (Paladines Rodríguez, 2007).

El problema carcelario requiere, desde hace muchos años, más presupuesto del Gobierno para mejorar la atención integral y el personal adecuado para una mayor coordinación entre las funciones legislativa, ejecutiva y judicial, con el fin de que se realicen o se adopten políticas que permitan darle solución y enfrentar la crisis carcelaria a corto y mediano plazo. La Corte no se ha pronunciado al respecto frente al debido proceso en el régimen disciplinario.

\section{España}

España se constituye como un Estado Social y Democrático de Derecho, que 
propugna como valores superiores de su ordenamiento jurídico la libertad, la justicia, la igualdad y el pluralismo político e, igualmente, presenta la Ley Orgánica General Penitenciaria, como régimen disciplinario en su capítulo IV para las personas privadas de la libertad y el debido proceso consagrado en el artículo 24 de la Constitución española del 1978.

[...] el régimen disciplinario ha de someterse a un criterio de razonabilidad y ajustarse a las garantías que consagran los tratados internacionales y las normas constitucionales (principio de legalidad, culpabilidad y responsabilidad subjetiva, estado de inocencia, in dubio pro reo, debido proceso legal, ne bis in idem y defensa en juicio). (Acurí, s.f.)

El régimen disciplinario de los internos se encuentra regulado en la Ley Orgánica General Penitenciaria 1/1979; el Real Decreto 1201/1981, por el que se aprueba el Reglamento Penitenciario, y el Real Decreto 190/1996, por el que se aprueba el Reglamento Penitenciario. Dicho régimen está encomendado a la administración pública, según lo establecido por el artículo 104 del Régimen Penitenciario. "En los establecimientos penitenciarios se guardará y mantendrá la disciplina necesaria para garantizar la seguridad y el buen orden regimental, y conseguir una ordenada convivencia". Esto con el fin de obtener un interés propio de la administración penitenciaria (Eguzkilore, 1993).

Existen unos tipos de elementos que tienen que ver con la vida en la prisión, como la convivencia debido a la tensión que resulta del aislamiento que ocasiona la creación de un conjunto de reglas que agrupe unos determinados aspectos de la conducta del interno.

Por dicho argumento, se encuentra consagrado este régimen disciplinario en la Ley Orgánica Penitenciaria 1/1979 en el capítulo IV, que clasifica en su artículo 42 numeral 1 las infracciones de los internos en muy graves, graves y leves; en el numeral 2, las faltas cometidas por los reclusos cuentan con unas medidas disciplinarias y de seguridad como aislamiento en celda (en general hasta catorce días), aislamiento (hasta de siete fines de semana), privación de servicios de salida (hasta dos meses), limitación de las comunicaciones orales al mínimo de tiempo reglamentario (durante un mes como máximo), privación de paseos $\mathrm{y}$ actos recreativos comunes (hasta un mes) y amonestación.

Las medidas de seguridad inspiradas en la doctrina del Tribunal Constitucional serán conducidas por los principios de necesidad, proporcionalidad y respetando los derechos fundamentales de los internos. Para la reducción de su medida correctiva, estipulada en el numeral 6, es necesaria la decisión del órgano colegiado correspondiente o a propuesta del equipo técnico, y cuando se advierta que hubo error en la aplicación de un correctivo se procederá a una nueva calificación, o, en su caso, a levantar inmediatamente el castigo.

En esta Ley, también se observa que las sanciones serán impuestas por el órgano colegiado correspondiente y en el caso de la utilización de los medios coercitivos, tendrán que ser autorizados por el director para impedir actos de evasión 
o de violencia de los internos, para evitar daños de los internos a sí mismos, a otras personas o cosas, para vencer la resistencia activa o pasiva de los internos a las órdenes del personal penitenciario en el ejercicio de su cargo.

\section{El Tribunal Constitucional estableció} la Sentencia 42/2008, de 10 de marzo de 2008; fue promovido un recurso de amparo respecto a los Autos del Juzgado de Vigilancia Penitenciaria de Alicante contra el centro penitenciario de Alicante por sanción disciplinaria. Vulneración del derecho a la asistencia letrada. El Tribunal Constitucional decidió levantar la suspensión que se le impuso al actor la sanción de 10 días de privación de paseos y actos recreativos.

\section{Metodología}

En este proyecto de investigación se utilizó el tipo de recolección de información documental, al momento de extraer información por medio de documentos, archivos teóricos, jurisprudencia y doctrina acerca del debido proceso en el régimen disciplinario en Colombia, Ecuador y España. El nivel de conocimiento en esta investigación es observacional, ya que se trata de verificar y observar el fenómeno que ocurre en los centros penitenciarios con respecto a la violación del debido proceso en los anteriores países, e igualmente, el descriptivo, por enunciar las cualidades que se dan de la eficacia del derecho anteriormente mencionado en los centros penitenciarios. Tiene también un enfoque básico; es decir, sin complejidades, para adquirir lo necesario del tema. Los métodos que se llevaron a cabo, es el inductivo, ya que se observó y estudió la problemática del debido proceso y el analítico, en el que descompone el fenómeno social de la investigación parte por parte. Se empleó el método histórico para ver el desarrollo de las normas que rigen el debido proceso dentro de los centros carcelarios; y sistemático, ya que se basa de una doctrina y una jurisprudencia para llegar a comprender. La metodología aplicada a este proyecto es cualitativa, porque incluye teoría documental. La técnica es la referencia bibliográfica mediante la utilización de un resumen analítico del tema planteado al inicio de la investigación.

\section{Discusión}

Después de comparar lo expuesto en la norma, la doctrina y la jurisprudencia, acerca de las garantías del debido proceso de los reclusos en los centros penitenciarios, se puede llegar a la conclusión que esta figura, en Colombia, Ecuador y España, según la normatividad de cada uno, es de obligatorio cumplimiento. En el caso de Colombia y Ecuador, en la Constitución Política de Colombia y Constitución de la República de Ecuador es consagrado como un derecho fundamental; y, por último, en España, en su Constitución española se presenta como una garantía constitucional, por tanto, se debe tener prevalencia sobre el derecho al debido proceso. Por consiguiente, de no ser así, se vulneraría este $y$ otros derechos que van de la mano, $y$ se tiene que dejar plasmado que se debe procurar por la reforma en los códigos carcelarios y la ley penal, con la finalidad de mantener disciplina, con equidad, igualdad $\mathrm{y}$, sobre todo, un gran apoyo 
Tabla 1. Cuadro comparativo

\begin{tabular}{|c|c|c|c|}
\hline \multicolumn{4}{|l|}{ Diferencias } \\
\hline & Colombia & Ecuador & España \\
\hline $\begin{array}{l}\text { Régimen de } \\
\text { Estado }\end{array}$ & $\begin{array}{l}\text { Tiene un régimen de } \\
\text { Estado Social de De- } \\
\text { recho, ya que sus polí- } \\
\text { ticas se fundamentan } \\
\text { en la protección de la } \\
\text { dignidad humana y } \\
\text { derechos fundamenta- } \\
\text { les de los ciudadanos. }\end{array}$ & $\begin{array}{l}\text { Tiene un régimen de } \\
\text { Estado de Derecho, } \\
\text { que logra el ejercicio } \\
\text { y la aplicación de las } \\
\text { normas consagradas } \\
\text { en la Constitución y los } \\
\text { valores vigentes en la } \\
\text { sociedad para asegu- } \\
\text { rar el respeto de los } \\
\text { beneficios jurídicos de } \\
\text { las personas. }\end{array}$ & $\begin{array}{l}\text { Tiene un régimen de } \\
\text { Estado Social y Demo- } \\
\text { crático de Derecho, que } \\
\text { se da a entender como } \\
\text { "Estado Social" aquel } \\
\text { que por medio de la ley } \\
\text { promueve y a proteger la } \\
\text { justicia social y bienestar } \\
\text { de todos sus ciudadanos; } \\
\text { y "Democrático de Dere- } \\
\text { cho", ya que los ciuda- } \\
\text { danos participan más o } \\
\text { menos en el gobierno de } \\
\text { la ciudad, pero sometido } \\
\text { a la ley. }\end{array}$ \\
\hline
\end{tabular}

El debido proceso es considerado como un derecho fundamental, según la Constitución en su artículo 29 y en

Constitución el Código Penitenciario y Carcelario en el artículo 134. Por tanto, se le debe dar ciertas garantías para su buen funcionamiento.
El debido proceso es considerado como un derecho fundamental, según la Constitución en su artículo 76, artículo 23 Nro. 27 que lo consagra entre los derechos civiles.
El debido proceso es considerado como una garantía constitucional en el artículo 24.2 de la Constitución española, la cual es aplicable a todos los órdenes jurisdiccionales y forma parte de los derechos que tienen un estatus especial en cuanto a garantías dentro del ordenamiento jurídico. Este derecho no se encuentra tácitamente en la Constitución.

\section{En Colombia se lleva a cabo la jurispru-} dencia por medio de sentencias de la Corte Constitucional para hacer respetar los

Jurisprudencia derechos fundamentales de la Constitución, como en los casos de la vulneración del debido proceso de los penitenciarios.

En Ecuador, la jurisprudencia se lleva a cabo por medio de sentencias de la Corte Constitucional, que también regula y se manifiesta frente a temas que tengan que ver con la Constitución, como lo es en el caso del debido proceso en los centros penitenciarios. No se encontró jurisprudencia alguna acerca del tema de investigación. 

medidas penales privativas de libertad, así como

-Rige el Código de Ejecución de Penas y Rehabilitación Social, el cual establece que

-Rige el Código Penitenciario y Carcelario, que regula el cumplimiento de las medidas de aseguramiento, ejecución de penas de las personas privativas de la libertad y de las medidas de seguridad, mediante el cual está plasmado todos los procedimientos que

Normatividad se tienen que llevar a cabo para que se dé la eficacia del debido proceso.

-En caso de una sanción disciplinaria, no se estipula en el Código Penitenciario y Carcelario la posibilidad de ser escuchado por medio de defensor público o privado. a los jueces de garantías penitenciarias les corresponde tutelar los derechos de las personas privadas de la libertad, tanto en el sistema progresivo como en el trato individualizado; mirando que se lleve a cabo el derecho fundamental al debido proceso, ya que ellos son los encargados.

-Establece que ninguna persona que esté privada de la libertad con un fin disciplinario puede ser aislada, torturada e incomunicada.

-Tiene un procedimiento para las sanciones breve, sencillo, oral que respete el debido proceso y el derecho a ser escuchado por sí mismo o por medio de defensor. la retención y custodia de detenidos, presos y penados, e igualmente promueve las actuaciones de la administración conforme al debido proceso estipulado en este.

-No se encuentra estipulado en la normatividad acerca del régimen disciplinario de los internos de manera tácita que las actuaciones procesales se deban seguir según el debido proceso.

\section{-El Real Decreto}

1201/1981 establece que por razón de las faltas cometidas se puede imponer aislamiento, que no podrá exceder de 14 días y se aplicará en los casos en que se manifieste una agresividad o violencia por parte del interno, o cuando altere, reiterada y gravemente, la normal convivencia en el centro. La celda deberá ser de análogas características a las otras. Para faltas graves y muy graves.

-En el Real decreto 190/1996 se encuentra el procedimiento cuando el interno incurra en una falta en un acápite aparte. 


\begin{tabular}{|c|c|c|c|}
\hline Doctrina & $\begin{array}{l}\text { Manuel Salvador } \\
\text { Rivera Agudelo (2009) } \\
\text { expone que en los } \\
\text { procesos disciplinarios } \\
\text { que adelanta la direc- } \\
\text { ción del INPEC o con- } \\
\text { sejos de disciplina son } \\
\text { violatorios del debido } \\
\text { proceso, puesto que } \\
\text { en última instancia } \\
\text { ello depende hasta del } \\
\text { mismo capricho de los } \\
\text { funcionarios encarga- } \\
\text { dos de la vigilancia de } \\
\text { las personas privadas } \\
\text { de la libertad. }\end{array}$ & $\begin{array}{l}\text { El doctrinante Ramiro } \\
\text { Ávila (2008) considera } \\
\text { tres principios que } \\
\text { son necesarios en los } \\
\text { procesos privativos de } \\
\text { libertad: ser oído y ser } \\
\text { defendido; ser oído y ser } \\
\text { presentado y ser oído } \\
\text { en un plazo razonable; } \\
\text { con el fin de que no se } \\
\text { vulneren los principios } \\
\text { constitucionales del } \\
\text { derecho a la defensa, se- } \\
\text { guridad jurídica, debido } \\
\text { proceso, tutela judicial } \\
\text { efectiva y a la libertad. }\end{array}$ & $\begin{array}{l}\text { El doctrinante Acurí } \\
\text { (s.f.) da a conocer que } \\
\text { el régimen disciplinario } \\
\text { ha de someterse a un } \\
\text { criterio de razonabilidad } \\
\text { y ajustarse a las garantías } \\
\text { que consagran los trata- } \\
\text { dos internacionales y las } \\
\text { normas constitucionales } \\
\text { (principio de legalidad, } \\
\text { culpabilidad y responsa- } \\
\text { bilidad subjetiva, estado } \\
\text { de inocencia, in dubio } \\
\text { pro-reo, debido proceso } \\
\text { legal, ne bis in idem y } \\
\text { defensa en juicio). }\end{array}$ \\
\hline Sanciones & $\begin{array}{l}\text { En el Código Peni- } \\
\text { tenciario se encuen- } \\
\text { tran faltas graves y } \\
\text { leves en el régimen } \\
\text { disciplinario, que } \\
\text { constituyen cuál es el } \\
\text { debido proceso que } \\
\text { se tiene que llevar a } \\
\text { cabo para imponer las } \\
\text { sanciones correspon- } \\
\text { dientes, según sea la } \\
\text { falta cometida, y estas } \\
\text { serán impuestas por } \\
\text { el respectivo Consejo } \\
\text { de Disciplina o por el } \\
\text { director del centro de } \\
\text { reclusión, garantizan- } \\
\text { do siempre el debido } \\
\text { proceso. } \\
\text {-Contra la decisión } \\
\text { que impone una } \\
\text { sanción procede el } \\
\text { recurso de reposición } \\
\text { y en subsidio de ape- } \\
\text { lación, ante el Consejo } \\
\text { de Disciplina. }\end{array}$ & $\begin{array}{c}\text { En el Código Orgánico } \\
\text { Integral Penal de este } \\
\text { país, las faltas discipli- } \\
\text { narias se clasifican en } \\
\text { leves, graves y gravísi- } \\
\text { mas y las respectivas } \\
\text { sanciones disciplinarias } \\
\text { previstas le corres- } \\
\text { ponden a la autoridad } \\
\text { competente del centro, } \\
\text { dependientes a la Cons- } \\
\text { titución y la ley. } \\
\text { - Las sanciones podrán } \\
\text { impugnarse ante el juez } \\
\text { o jueza de garantías } \\
\text { penitenciarias. }\end{array}$ & $\begin{array}{l}\text { En este Código Peni- } \\
\text { tenciario se encuentran } \\
\text { faltas muy graves y } \\
\text { leves en el régimen, y las } \\
\text { sanciones disciplinarios } \\
\text { ocasionadas por estas } \\
\text { faltas serán impuestas } \\
\text { por el correspondiente } \\
\text { órgano colegiado, cuya } \\
\text { organización y composi- } \\
\text { ción serán determinadas } \\
\text { en el reglamento. } \\
\text {-La interposición de } \\
\text { recurso contra resolu- } \\
\text { ciones sancionatorias } \\
\text { suspenderá la efectivi- } \\
\text { dad de la sanción, salvo } \\
\text { cuando por tratarse de } \\
\text { un acto de indisciplina } \\
\text { grave la corrección no } \\
\text { pueda demorarse y los } \\
\text { que impongan la sanción } \\
\text { de aislamiento en celda } \\
\text { serán de tramitación } \\
\text { urgente y preferente } \\
\text { y el director del esta- } \\
\text { blecimiento remitirá el } \\
\text { expediente disciplinario } \\
\text { al juez de vigilancia. }\end{array}$ \\
\hline
\end{tabular}




\section{Semejanzas}

-En Colombia y Ecuador, el debido proceso es considerado como un derecho fundamental, por lo que se debe de garantizar su protección.

-Colombia, Ecuador y España garantizan el debido proceso en los centros penitenciarios.

-En Ecuador, Colombia y España, el debido proceso dentro del régimen penitenciario debe ser justo, oportuno y equitativo.

-En Colombia y Ecuador, el debido proceso en el régimen penitenciario tiene la obligación de contar con una justicia independiente, que respete la Constitución, tratados internacionales y el principio de legalidad.

-En Colombia, Ecuador y España, el debido proceso en el régimen penitenciario ha evolucionado significativamente, brindando cada que transcurre el tiempo mejores garantías a los internos

- Ecuador, al igual que Colombia, tiene Corte Constitucional que por medio de jurisprudencia regula y defiende lo estipulado en la Constitución.

-En España, Ecuador y Colombia, el régimen disciplinario se venía caracterizando por la dureza de las sanciones, la inseguridad jurídica que produce la redacción de los tipos de faltas y la ausencia de un procedimiento disciplinario.

-En España y Ecuador se lleva a cabo un procedimiento riguroso y al interponer un recurso se trasladará al juez competente.

-En Colombia y España al momento de la realización del proceso correspondiente no se pueden ser escuchados a través de defensor público o privado.

-En Colombia y España se encuentra jurisprudencia acerca del debido proceso en el régimen disciplinario de los internos.

-En Ecuador y Colombia se encuentra tácitamente el derecho al debido proceso en la legislación correspondiente con respecto al régimen disciplinario de los internos.

del Estado; por el motivo de que en el momento de practicar las sanciones con el debido proceso correspondiente, según las faltas cometidas, garantice el orden de los centros carcelarios, la protección de los derechos fundamentales y la seguridad de los reclusos.

\section{Conclusiones}

- Con respecto a la normatividad del debido proceso, se deduce que en Colombia y Ecuador este forma parte de un derecho fundamental, el cual necesita una protección y unas mínimas garantías para su efectividad. Para España, es una garantía constitucional, la cual le proporciona un nivel más alto en su ordenamiento. Todo lo anterior, fundado en los artículos de las constituciones correspondientes de cada país. Este derecho dentro del régimen disciplinario de los internos de los países, 
objeto de estudio, cuentan con normas que protegen, regulan y preservan los derechos de los reclusos.

- De la doctrina se deduce que esta se basa en los principios e ideas de los autores, que, en este caso, investigan las sanciones disciplinarias del régimen disciplinario, donde se observa que prima el debido proceso en el régimen disciplinario en los países objeto de estudio.

- Con respeto a la jurisprudencia, existen diferentes Cortes que velan por que se cumpla el debido proceso en el régimen disciplinario, las cuales ofrecen una mayor protección y garantías mínimas para que no se vulnere este derecho a los internos de los establecimientos penitenciarios, que tienen un nivel especial dentro de cada ordenamiento jurídico, dándole un carácter de obligatoriedad. Pero en Ecuador, a diferencia de las otras, no se encuentran pronunciamientos de la Corte Constitucional acerca de la protección del debido proceso en el régimen disciplinario dentro de la investigación realizada.

\section{Impactos social y económico}

La toma de decisiones penitenciarias sigue apostando por la protección de los derechos fundamentales que acogen a la población más vulnerable, como lo son las personas privadas de la libertad. Este enfoque aboga por la construcción de nuevos métodos aplicables a este sistema penitenciario para evitar la violación al debido proceso, para que mejoren las condiciones de vida de los internos y faciliten su pleno desarrollo y rehabi- litación en los centros penitenciarios. Igualmente, evita la arbitrariedad de los directivos o funcionarios del INPEC al imponer una sanción. En cuanto a lo económico, se podría decir que se evitarían los gastos de la administración en los procesos sobre las acciones de tutelas interpuestas por los reclusos por la violación al debido proceso.

\section{Referencias}

1. Acurí. (s.f.). Principios y normativa del régimen disciplinario.

2. Agencia Estatal Boletín Oficial del Estado. (1978). Constitución española. https:// www.boe.es/legislacion/documentos/ ConstitucionCASTELLANO.pdf

3. Agencia Estatal Boletín Oficial del Estado. (2018). Código Penitenciario de España. file:///C:/Users/estudiantegenerico/Downloads/BOE-054_Codigo_Penitenciario.pdf

4. Agencia Estatal Boletín Oficial del Estado. (1996). Reglamento Penitenciario. https://www.boe.es/boe/dias/1996/02/15/ pdfs/A05380-05435.pdf

5. Barón, R. (1993). Régimen penitenciario y carcelario. http://epn.gov.co/elearning/distinguidos/LEGISLACION/12_rgimen_penitenciario_y_carcelario.html

6. Borja, M. (2009). Violación de las garantías constitucionales de los derechos humanos y el debido proceso en la aprehensión por delitos flagrantes y la prisión preventiva. http://repositorio.uasb.edu.ec/ bitstream/10644/1148/1/T0774-MDE-Borja-Violaci\%C3\%B3n\%20de\%20las\%20garant\%C3\%ADas\%20constitucionales.pdf

7. Código Penitenciario y Carcelario de Colombia. (1993). http://www.secretariasenado.gov.co/senado/basedoc/ ley_0065_1993.html 
8. Constitución de la República de Ecuador. (2008). http://www.wipo.int/edocs/lexdocs/laws/es/ec/ec030es.pdf

9. Constitución Política de Colombia. (1991). http://www.secretariasenado.gov. co/senado/basedoc/constitucion_politica 1991.html

10. ¿Cuántos presos hay en las cárceles españolas? (2016). http://www. europapress.es/nacional/noticia-cuantos-presos-hay-carceles-espanolas-20160225142144.html

11. Ley 1709 de 2014. "Por medio de la cual se reforman algunos artículos de la Ley 65 de 1993, de la Ley 599 de 2000, de la Ley 55 de 1985 y se dictan otras disposiciones". 20 de enero de 2014. Diarios Oficial, 49.039 .

12. Machado, F. (2017). Un $42 \%$ de hacinamiento existe en los centros penitenciarios de Ecuador. El telégrafo. https://www.eltelegrafo.com.ec/ noticias/39/13/un-42-de-hacinamiento-existe-en-los-centros-penitenciarios-de-ecuador

13. Paladines Rodríguez, J. (2007). La desnudez del garantismo. El detenido y la efectividad de sus garantías en Azuay y El Oro. Quito, Cuenca y Machala. Universidad Andina Simón Bolívar.
14. RamiroÁvila,S.(2008).Larehabilitación no rehabilita: la ejecución de penas en el garantismo penal. En: Ejecución penal y derechos humanos, una mirada crítica a la privación de la libertad, ed. Carolina Silva Portero. Quito: Ministerio de Justicia, Derechos Humanos y Cultos, 149.

15. Rivera, M. (2009). La disciplina y el problema de las cárceles en Colombia. Pensamiento y Poder, 1(4), 23-25. http:// fer.uniremington.edu.co/ojs/index.php/ PYP/article/view/111

16. Salgado, M. (2000). Conferencia regional sobre situación carcelaria en la Región Andina. http://www.inredh.org/archivos/pdf/carceles2000.pdf

17. Subdirección de Asesoría Jurídica de la PGE. (2006). Código de Ejecución de Penas y Rehabilitación Social de Ecuador. http://perso.unifr.ch/derechopenal/assets/files/legislacion/l_20120608_01.pdf

18. Tribunal Constitucional de España. (2016). Recuperado de https://www.tribunalconstitucional.es/es/Paginas/default.aspx 